\title{
A precarização de políticas públicas e suas repercurssões na auto-sustentação dos kaingang do oeste catarinense
}

\section{Neusa Marıa Sens Bloemer}

\author{
Unıversıdade do Vale do Itajaı Itajaı Brasıl
}

neusabloemer@hotmall com

\author{
Aneliese Nacke \\ Nucleo de Estudo dos Povos Indigenas Flonanopolıs Brasıl \\ anehesenacke@hotmall com
}


Resumo

Este artıgo trata da população kaingang no oeste catarinense localızada nas areas indigenas de Xapeco Toldo Chimbangue Toldo Pinhal Toldo Imbu e Aldera Conda terras que se encontram em diferentes condições jurıdıcas A sıtuação socioeconômica deste povo comprova que as politicas publicas não atendem as suas demandas e reıvındıcações dıfıcultando a reprodução socıal das unidades familiares especialmente daquelas que resistem ao modelo de agricultura produtivista Neste processo fica caractenzado que o Estado brasileiro continua se omitindo como o fez historicamente no atendimento as solıcıtações dos indigenas bem como de suas responsabilidades descumprindo o que determina os direitos constitucionais desses povos

Palavras-chave politicas publicas terras indigenas Kaingang
Abstract

This paper examines the Kaingang population in the west of Santa Catarina State located in the indigenous areas of Xapeco Toldo Chimbangue Toldo Pinhal Toldo and Imbu Village Conda territories which present different legal statuses The socioeconomic situation of this group demonstrates that soctal and welfare policies do not meet their demands and claims hindering the soctal reproduction of famly units especially those who resist the model of commercial agriculture In this process it is clear that the Brazilian State contmues to fatl as it has in the past to attend to the demands of the Indians as well as to its responsibilities nolating the constitutional rights of these peoples

Keywords public polictes indian reserves Kaingang 


\section{Apresentação} presente artıgo é uma reelaboração de parte dos conteudos
apresentados no livro intıtulado ${ }^{1}$ Os Kaıngang no Oeste Catarınense tradıção e atualıdade, cuja publıcação foı viabılızada pelo convênı estabelecido entre a Fundação de Ciêncıa e Tecnologıa de Santa Catarına - Funcitec, atualmente denommada Fapesc

O conhecimento atualızado sobre a realıdade vivida pelos indígenas deve ser uma das priondades dos estudos etnológicos, necessárıos, inclusıve, para a implantação de polítıcas públıcas, que atendam as demandas dessas populações, garantındo seus direıtos e respeıtando as suas especificıdades culturais

Esta versão é uma síntese relatıva à sıtuação atual das terras kaıngang bem como às estrategıas de exploração para a autosustentação das famılıas indıgenas, consıderando-se a ıdentıdade diferenciada kaungang

Como recurso metodologico, recorreu-se a dados qualitatıvos e quantitativos, fontes documentais e historicas, a dados estatisticos e a laudos antropologicos Visitamos e entrevistamos os indígenas em suas aldeıas para ouvı-los em suas reıvindıcações, constatar suas satısfações, descontentamentos e condições de vida

Em diversas etapas de campo nas visitas às diferentes terras indigenas, realızadas nos anos de 2004 e 2005, executou-se, paralelamente, a aplıcação de questıonarıos aos agentes de saude, professores e lıderanças indígenas

\section{Histórico}

Na reglão que hoje corresponde ao oeste catarinense, os indígenas tıveram suas terras expropriadas a partır da ocupação dos campos de 
Guarapuava e de Palmas, datadas em 1938 e 1948, respectıvamente Ate então, para o estado brasıleıro, a area em questão consıstıa num ımenso "vazıo demográfıco", que punha em rısco a integrıdade do terrıtorıo nacional Nesta visão, a presença indígena representava obstáculo ao domínıo e exploração dessas terras Assım, uma das estrategıas utılızadas pelo conquistador for a cooptação de lıderanças indígenas para a elımınação ou o submetımento das facções kaıngang hostıs

Diferentes ações foram deflagradas para vıabılızar a ocupação dessas terras, que tanto cumpırıam a função de guardıã do terntóno quanto assegurarıam a sua exploração econômıca Em 1836, o governo da provincıa de São Paulo a qual a regıão pertencıa, crıou um "destacamento de permanentes" para os Campos de Palmas, com o objetuvo de promover a exploração dos recursos existentes, bem como o de proteger os novos povoadores que alı se estabelecessem (Renk, 2007, p 18)

A criação das colônias militares de Chapecó e Chopım, nos Campos de Palmas (Decreto n 1 318/1854) atendıa as mesmas preocupações A primeira delas fol instalada onde se situa a atual sede do municípıo de Xanxerê, em 14 de março de 1882 O decreto de criação definıa como objetıvos a defesa da fronteira a proteção dos novos habitantes contra a incursão dos índıos, a cıvılızação dos indıgenas através da catequese e o povoamento da área por agricultores Contudo, a unıcıatıva não obteve o sucesso esperado $O$ fracasso fol atribuído à falta de apoı do governo imperıal no atendimento as necessıdades da referida colônıa milıtar

À mesma época, em 1881, houve a desıgnação de um diretor de índıos para a região de Palmas, cuja função era atender a população ındıgena que vivıa em sıtuação de desamparo Atendıa tambem à solıcıtação dos proprıos colonızadores que não se dispunham a arcar com os custos de manutenção dos undigenas que sobreviveram ao processo de espolaç̧ão dessa fração de seu terrıtorıo pela frente pastorll que a ocupou Não se pode delxar de mencionar ainda que

[ ] o excedente da população trabalhadora das fazendas de criar mstaladas nos Campos de Palmas Erê Iranı e Lages deslocou se ao sul da região de Chapeco e ao norte na região de Mangueirunha e no Planalto de Canoinhas alcançando a zona de pınheiros e matos dedıcando se a pequena lavoura a extração de madeıra e erva mate A atıvidade agrıcola 
e a undustria extratıva foram postenores e a margem da pecuarıa atraindo a fração de menor capital econômıco (Renk 2007 p 21)

De fato, conflitos decorrentes de disputas sobre limites geopolítıcos marcaram a regıão O primeıro deles entre Brasıl e Argentına, orıgınou a Questão de Palmas ou Missões, tendo sıdo solucionado em 1895, atraves da arbitragem do então presıdente dos Estados Unudos da America, que deu ganho de causa ao Brasıl Somente em 1903 os limites entre o Brasil e o país vizınho foram finalmente fixados

Por outro lado, ate 1916, a posse da região dos campos de Palmas esteve em litıgıo entre os governos do Parana e de Santa Catarina A questão foı resolvida pela intervenção do presıdente da repúblıca Wen ceslau Braz, por cuja decısão grande parte das terras que constıtuıam os Campos de Palmas passou a integrar o estado de Santa Catarına

Com o mesmo proposito de colonızar a regıão, em 1889, o governo umperıal concedeu à Estrada de Ferro São Paulo - Rıo Grande do Sul, terras devolutas e nacionaıs, ao longo da ferrovia a ser construida, cujo trajeto atıngıa os vales dos rıos Negro, Iguaçu, Peıxe e Uruguaı

Essa concessão foı transferıda para a Brazıl Raılway Company, que, por sua vez, transferıu as terras recebıdas para sua subsıdıarıa, a Brazl Development $\&$ Colonızatıon Co Posterıoımente, esta companhia, atrıbuuu a várıas empresas colonızadoras a tarefa de efetıvar o povoamento das glebas recebıdas São estas empresas que promovem a ocupação da região por frente agrícola composta prıncıpalmente de ımıgrantes orıgınarıos do estado do Rıo Grande do Sul

Não e dificl imaginar, consıderando a extensão de terras desapropriadas, o grande contıngente de indigenas ${ }^{2}$ e caboclos expulsos para dar lugar as novas populações que chegavam a região

Para os indígenas, particıpantes e vítumas desse processo o governo do estado do Parana - que no mícıo do seculo detınha jurısdıção sobre a regıão - reservou duas áreas de terras, Xapeco e Palmas, hoje Terra Indigena (TI) Xapeco e TI Palmas, nas quais parte dos indigenas e dos seitanejos desalojados se refugiaram Outro contıngente permaneceu dısperso pela região, sem, contudo, perder sua identıdade etnuca Seus descendentes, a partır da decada de 1980, organızaram-se para reıvndıcar a recuperação de frações de seus antıgos terrıtorıos, reagundo, paralelamente, aos preconceitos e a dıscrımınação sofrıdos historıcamente 
O confronto que se estabeleceu com as diferentes frentes que atıngıram a região em foco caracterıza uma relação de frıcção interétnıca (Olıveira, 1976), na qual os Kaungang vivencıam a condıção de inferıondade, numa relação assımétrica e hıerarquizada, que teve como resultado a perda de uma autoıdentıfıcação posıtıvada

\section{A constıtuıção das áreas kaungang}

Os Kaingang constituem um dos povos indigenas mais numerosos do Brasıl Sua população de aproxımadamente 25000 habıtantes concentra-se, em sua maiona, nas TIs localızadas em São Paulo, Parana, Santa Catarma e Rıo Grande do Sul ${ }^{3}$ Uma parcela deste total vive em áreas em processo de regularızação, especıalmente, nos doıs últımos estados Outra parte reside na periferia de centros urbanos ou na zona rural, e, nessas condıções, não recebem, ou recebem apenas parcıalmente, a assıstêncıa dısponıbılızada aos ındígenas sıtuados nas TIs

No que se refere ao Estado de Santa Catarina, mais precisamente na região oeste, dados fornecidos pela Funasa $(2003$, p 3 ) indicam que o contungente undígena localızado nas TIs Xapecó, Toldo Chumbangue e Toldo Punhal, somado à população das áreas aunda em processo de constıtuıção, Toldo Imbu, Aldeıa Condá, Toldo Chımbangue II e Toldo Pınhal II e Aldeıa Kuprı, totalıza 5025 indıvíduos ${ }^{4}$ E umportante ressaltar que, embora a população kaingang represente maıorı absoluta, estão mcluídos nesses totais membros das etnuas Guaranı e Xokleng

As atuais TIs encontram-se localızadas em territonos tradıcıonais Kaingang representam, contudo, fração ínfuma dos espaços ocupados antes do processo de colonızação Ressalte-se que a concepção kaungang de territóno ultrapassa evidentemente as fronteiras das terras a eles destunadas pelo Estado brasıleuro Estão incluídos, nessa concepção, os locais nos quars estão enterrados os seus antepassados e os seus "umbigos e onde pretendem enterrar suas cabeças Esta percepção é evidenciada especialmente nos movimentos indígenas Kaungang pela recuperação das terras tradıcionais Para Tommasıno, o territorı kaingang

[ ] comporta varios grupos locals onde se distribuem parentes e afins Nesse espaço fisico grupos familiares (extensos ou não) e pessoas se movem constantemente formando uma ampla rede de sociabilidade cujos individuos compartılham uma experıência hıstorica e se 
consideram participes da mesma cultura Unifica os portanto uma consciência mitıca historica e etnica Essa rede configura o todo social que expressa a unidade sociopolitica mais ampla (1995 p 10)

Esta rede de sociabilıdade, que se estende para outras TIs Kaingang propıcıa a cırculação dos indıvíduos ou das unıdades famılıares, motıvada por visitas a parentes, busca de cônjuges de trabalho, ou de refugıo, quando a sıtuação na terra de orıgem se torna insustentável por motıvos politıcos e econômıcos

Dentre as TIs Kaingang hoje existentes no estado, a denominada Xapecó é a que apresenta maıor dımensão, tendo sıdo a prımeıra a ser constıtuida como terra indıgena Situada nos munıcípıos de Ipuaçu e Entre Rios, apresenta uma area de 15623 hectares, cerca de 1/3 dos cinquenta mil hectares reservados aos Kaingang em 1902 (decreto n 7 de 31/12/1902) Segundo a historia oral dos indigenas, a doação constıtuıu pagamento pelos servıços prestados pelos ındıgenas liderados pelo cacıque Vaıcrê, na abertura da estrada que lıgava os Campos de Palmas aos do R1o Grande do Sul (Santos, 1970, p 44) Vivem nesta TI os indígenas das etnıas kaungang e guaranı, formando um contıngente de 3995 indıvíduos Os Kaingang somam 3721 pessoas $^{5}$ (FUNASA, 2002, p 3)

$\mathrm{Na}$ TI Xapecó, os Kaingang reıvındıcam a recuperação de 660 hectares contıguos a área undıgena Em abril de 2007, o minıstro da Justıça assınou portarıa declaratórıa desta terra Deve-se regıstrar, aunda, a solıcıtação dos Guaranı da aldeıa Lımeıra, localızada nesta TI, de uma terra específica para os integrantes deste grupo étnıco Ate o momento não ha provıdêncıas sobre essa reıvındıcação

Integrada ao "territono tradıcıonal kaungang" encontra-se a TI Chımbangue, localızada as margens dos rıos Iranı e Lajeado Lambedor distante $18 \mathrm{~km}$ do centro da cıdade de Chapecó

A ocupação imemorial do Toldo Chımbangue pelos Kaingang possibilitou recuperar parte de suas terras que foram regularizadas em 1985 pelo governo brasileiro, depois de uma longa luta politica empreendida pelos proprıos Kaingang mas também apoıada por segmentos da sociedade civil

Este processo estendeu-se ate 30 de dezembro de 1985 quando, finalmente, por acordo politico, determunou-se, naquele momento, que 
seriam reconhecidos e demarcados 988 hectares, metade das terras reıvindıcadas pelos Kaungang do Toldo Chimbangue ${ }^{6}$ A decısão for ofıcialızada pelo Decreto Presıdencial nº 92 253/85

Absolutamente convencidos da necessidade de possuur a terra para se manter e se reproduzır como grupo étnico diferenciado, os Kaingang do Chumbangue contınuam lutando para que as terras ıdentıfıcadas e reconhecidas pelo governo brasılerro em 19857, como suas, sejam demarcadas o mais rápıdo possível Este ato resultara na amplıação da Terra Indígena Chımbangue, acrescentando 975 hectares aos 988 já demarcados e devidamente registrados

A portaria que declarou como area indigena a locahdade de Sede Trentın for assinada em 2000 Esta área vem sendo denominada de Chımbangue II, e encontra-se legalmente na situação de "declarada" pela Portarıa Declaratórıa - PD 1535 de 19/I 1/2002 Falta, contudo, o pagamento da undenızação para os ocupantes não-ındıos que aunda se encontram estabelecidos naquelas terras (FUNAI, 2007) Há um impasse fundado na dıscordâncıa dos agrıcultores quanto a proposta de indenızação apenas das benfeitorias e não das terras tal como ocorreu em 1985

Situado no municípıo de Abelardo Luz, o Toldo Imbu abriga, atualmente, 19 famílıas, totalızando uma população de aproxımadamente 96 pessoas Em abrıl de 2007, o munustro da Justıça assınou Portarıa Declaratórıa assegurando aos indigenas 1965 hectares de terras locallzadas no municipio de Abelardo Luz De acordo com a Funal, em 2007, a população no Toldo Imbu somava 101 indıviduos (FUNAI 2007b)

Esta area encontra-se ıdentıficada e delımıtada Ha uma ação cıvıl públıca por parte do Mınıstérıo Publico Federal contra o Mınıstérıo da Justıça e a Funaı solıcıtando a regularızação ımedıata destas terras Para tal, falta a portarıa declaratórıa e a indenızação de benfeıtorıas dos ocupantes não-ındıos que lá vıvem (FUNAI, 2007a)

Localızada no munıcípıo de Seara, dıstante 35 quilômetros da sede do munıcípıo, a TI Pınhal conta com uma população aproxımada de 117 pessoas $^{8}$, compondo suas 30 famúlıas

Em 14 de maio de 1998, fol criada a TI Toldo Pınhal, com uma área de 880,07 hectares de terras Em 2003 o Grupo de Trabalho encarregado de analısar a sıtuação ıdentıfıcou uma área de 4846 hectares 
como terra indígena Contudo, somente em abrıl de 2 007, Portarıa Declaratórıa do Mınısterıo da Justıça reconheceu 3965,93 hectares (FUNAI, 2007a) que somados aos 880,07 hectares ja regularizados atendem ao recomendado pelo GT acima referido

No Toldo Pinhal, em 1999, havia 121 pessoas Havia tambem a expectativa, a epoca de que este numero pudesse aumcntar com o retorno de outras pessoas que se consideravam pertencentes aquela terra, o que levou os indıos a manter sua posıção - regıstrada no laudo antropologico ${ }^{9}$ - sobre a demarcação de 8890 hectares

Os Kaingang hoje localızados na Aldeıa Conda já vıveram sıtuação de penuria e unsegurança quando estıveram abrigados em barracos cobertos com lona no centıo de Chapeco Eles sempre estiveram es tabelecidos no centro de Chapecó, mas fol a partır da decada de 1990 . com o crescimento da cidade ${ }^{10}$ que estes indıos adquiruram visibilidade, motıvando muitas polêmıcas e discussões em diversos setores admunıs tratıvos locals Acusados de "sujos", pi eguiçosos", promovedores de prostıtuıção por alguns, ou defendıdos por ONGs, CIMI e outras instıtuıções, vıvencıaram uma experıêncıa extremamente negatıva

Sua transferêncıa exıgıu, prelımınarmente, a elaboração de um estudo antropologıco ${ }^{11}$, que comprovou a ıdentıdade indígena kaingang O relatórıo decorrente deste estudo, intıtulado "Identıfıcação das famılıas kaıngang resıdentes na cıdade de Chapecó" subsıdıou as decisões postenormente tomadas pela Funal, ou seja, a remoção para a atual area em que se encontram a Aldesa Conda

No periodo em que fol elaborado o laudo antropologico, havia 212 pessoas $^{12}$, constıtuıdas em 64 famílias, resıdındo no centro de Chapeco $\mathrm{A}$ maıorı desta população era nascida em Chapeco, mas havia, entre eles, indıos provenientes de Nonoal, Irau e Guarıta Na percepção dos Kaingang, resıdır em Chapeco sıgnifıca que estão apenas circulando em seu territono tradıcional, que a seu ver não esta restrito aos limites das TIs e tampouco aos limites estaduais ou municipars convencionados pela sociedade envolvente Ha outros valores e parâmetros que marcam os lımites da area territorial indigena, assocıados ao seu corpo de crenças e mitos

No que dız respeıto a area, há aında uma ındefınıção que vem prejudıcando a organızação do grupo Por tratar-se de uma area 
que sofrerá ınfluência da construção da hidreletrıca Foz do Chapecó, houve um acordo entre o governo federal e o Consorcio Foz do Chapeco Na ocasıão, fol furmado um "termo de compromısso' no qual o empreendedor deverá adquirur I 500 hectares de area para a formação da reserva indígena, cabendo à FUNAI adquirur o restante A FUNAI já fez a aquisıção de 30503 hectares que vêm sendo ocupados pela comunidade indigena (FUNAI, 2007) Entretanto, o referıdo Consórcıo ate o momento, adquirıu apenas 943 hectares, totalızando assim uma área de 1248 hectares $^{13}$ É nesta área que os Kaıngang estão vıvendo, em condıçốes precarıas de habıtação e sem espaço defınıdo para plantaı suas lavouras

\section{As terras kaingang e a produção de subsıstência}

Na TI Xapeco, a unstalação do posto undigena em 1941, marcou o inıcıo da exploração intensıva dos ı ecursos das terras da reserva $\mathrm{A}$ polítıca de autofınancıamento implantada pelo orgão de assıstêncıa for a justıfıcatıva para o arrendamento das terras a agrıcultores não ındígenas, para a instalação de serrarıa, que promoveu a exploração da rıca cobertura florestal da área e para a implementação de projetos agricolas de cunho desenvolvimentısta

Em termos ambientaıs, pode-se constatar que a degradação ocorrıda na TI Xapeco não foı dıferente do restante da região Assım, quando os undigenas dos toldos Chımbangue, Pınhal e Condá foram realocados para as áreas recuperadas na decada de 1980 encontraram terras exaurıdas quanto à fertılıdade, alem da escassez de recursos florestais e anımais, ambos necessarıos para a sua sobrevivência nos moldes tradicionais

Não se pode deıxar de mencionar, portanto, que a alteração ambıental afetou diretamente o modo de subsistêncıa tradıcıonal desse povo, baseada na coleta e na caça, enquanto a agricultura era consıderada uma atıvidade secundarıa Afırma Melıá

Não parece haver no sistema atual kaungang quase nenhuma contınuidade com o sistema tradicional Talve $z$ por dois motivos o primeiro e ecologico, fruto da redução das areas de coleta e caça e o segundo e fruto da pressão da ideologia envolvente que não reconhece a coleta e a caça como importantes no processo produtıvo Consequentemente ocorreu o avanço da dependêncıa da agrıcultura ${ }^{14}$ 
Desaparecıda quase totalmente a possıbılıdade da caça e da coleta, restou aos Kaungang, além da prátıca agrícola para o sustento das famílıas, a venda da sua força de trabalho, executando serviços para os regıonaıs como dıarıstas Esta prátıca foı incentıvada tanto pelo órgão de assistêncıa, no caso da TI Xapeco, quanto pelo contexto regıonal que era essencialmente agricola - principalmente para os indios que viviam como agregados em terras de colonos, como ocorreu com os Kaingang do Toldo Chımbangue e do Toldo Pinhal

As atıvidades agrícolas contınuam organızadas em torno do grupo domestıco ${ }^{15}$, sendo esta uma pratıca usual de todas as famılıas kaingang A maior parte dos grupos doméstıcos realıza roças de pequenas dımensões, cultıvando produtos como o milho, o feı̃ão e o arroz, destınados em parte à comercıalızação, e produtos para o consumo familiar, como a abobora, mandıoca, batata doce, batatunha , amendoim, melancia, pepıno e algumas verduras No Toldo Pinhal e no Toldo Chumbangue produzem e comercializam tambem a erva mate

A respeito da dıvısão das atıvidades de trabalho, há que se des tacar que a produção de milho e feı̃ão, potencialmente destınada ao mercado, e uma atıvidade desenvolvida pelos homens, por vezes em forma de "puxırão"16 Assim, cabe as mulheres kaingang cuıdar da produção agnicola para autoconsumo, o que não as lıbera de prestar ajuda nas lavouras de milho e feujão

Mutas famílias utılızam em suas roças a tecnıca do roçado e da queımada, fazendo, posteriormente, o plantı manual e, por vezes, empregando a tração anımal Exıstem ainda as lavouras realızadas com o recurso da mecanızação, quando há equipamentos dısponıveıs

Além das roças de pequena monta, ha o plantıo extensıvo de soja e milho, na TI Xapecó, realızado por poucas famılıas O cultıvo extensıvo nos moldes promulgados pela agrıcultura produtıvısta não tem sıdo facl para os Kaingang, como, alıas, para todos os produtores famuliares do país Por tratar se de um sistema que demanda altos investimentos, tanto em insumos, quanto em tecnologıa, além de privilegıar a monocultura, opõe-se as formas tradıcıonaıs de agricultura

Esta polítıca agrícola teve como uma de suas consequêncıas a perda de algumas pratıcas da cultura tıadıcıonal do grupo e sua unserção 
no mercado regional Em outros termos, o que se quer destacar e que ao "aderır" a esta agricultura produtıvista, esses indıgenas deixaram de transmitir os seus saberes tradicionals aos seus descendentes, como, por exemplo a prática da "colvara" ${ }^{17}$ Em consequência, necessitam dominar novos saberes, cuja complexidade exıge conhecimentos tecnicos desconhecidos pelos indigenas, alem de recursos econômicos para a realızação deste modelo de agnıcultura os próprıos indıgenas expressaram preocupação com a contamınação de suas fontes de agua e a ocorrência de casos de intoxicação

Outro aspecto a ser ressaltado diz respeito a perda da autonomia dos grupos familiares sobre o processo produtivo Eles passam a depender diretamente de polítıcas governamentais que atendam as suas necessidades para produzır dentro do novo modelo Esta dependência fol registrada ao longo do processo dos recorrentes projetos desenvolvimentıstas umplementados por meıo da atuação assıstencialısta histórıca da Funaı Assım, a cada safra, os Kaingang dependem de fornecumento de sementes e insumos agrícolas destunados a correção de solo, e fıcam a mercê, muıtas vezes, de auxılıos provenıentes de orgãos munıcıpaıs, estaduais ou de associaçõcs com agrıcultores regionais para a implementação de suas lavouras

Estudos recentes têm chamado a atenção sobre o modo de produzır camponês e ındıgena, que se retroalımenta do multıuso de seu proprio ambiente Conforme Toledo

Em uma exploração camponesa tıpıca o ambıente natural e o transformado convertem se em uma complexa parsagem semelhante a um mosaico em que culturas agricolas poustos florestas primarias e secundarıas hortas domestıcas pastos e cursos d agua são segmentos de todo o sıstema de produção [ ] Essa estrategıa multıuso atraves da qual os camponeses mantêm e reproduzem seus sistemas produtivos constituı uma caracteristica ecologicamente valıosa que tende a conservar os recursos naturais garantındo a diversidade ambiental e biologica (Toledo 1998 p 28)

No caso especifico da TI Chimbangue, constatou-se que a atıvidade agrícola dos grupos domésticos depende de fornecimento de in sumos que são obtıdos junto a orgãos estaduals, munıcıpais e federais Esse grupo executa as lavouras com o auxilıo de um trator em terras de topografia adequada para tal, mas, em grande maiona, undicam que 
há insuficiêncıa de equipamentos agrícolas de credıto e de incentıvos Essa insuficiêncıa e demonstrada no reduzıdo número de famílıas (um total de 20), que recebem apoı para a realızação das lavouras através do Pronaf Este apoio e de R\$ 1 000,00 por familia a cada safra

Apesar da precariedade, aunda assim ha famillas que se "destacam" - como expressou um tecnico agrícola -, havendo na TI Chimbangue uma famílıa que colheu 80 sacas de feı̃ão, 60 sacas de soja e 500 sacas de milho na safra 2002/03 Conforme o mesmo tecnico, "trata-se de um bom plantador", o que torna evidente que esta não é a regra

Quanto aos equipamentos destınados à produção agrıcola, constatou-se que na TI Xapecó o preparo de terras atraves da mecanızação ocorre especialmente nas aldeıas Sede Pinhalzınho e Linha Guaranı Nesta TI ha três tratores, uma colheitaderra, uma plantadeira, um pulverızador, uma grade, um camınhão, uma carreta agrícola e uma roçadeira Parte deste equupamento pertence a Cooperındıgena As TIs Pınhal e Toldo Chımbangue dıspõem de apenas um trator cada, além de juntas de bol, arados, grades e plantaderras, uma vez que boa parte das lavouras é realızada com a utılızação de tecnologı sımples

No que diz respeito ao apoio tecnico apenas na TI Xapeco constatou-se a presença de técnico agricola remunerado pela comunidade atuando na aldeıa Sede Nas aldeıas Agua Branca e Pınhalzınho, técnıcos agnicolas são remunerados pela prefeıtura do munıcıpıo As demaıs TIs, como Toldo Imbu, Toldo Pınhal e Toldo Chumbangue e Aldeıa Conda, não têm recebıdo com regularıdade a orıentação de técnico agiıcola, o que resulta em descontentamento por parte dos indigenas, que expressam, inclusıve, a necessidade de um tecnıco que orıente para uma agricultura orgânıca, dıferente daquela propria do modelo produtıvısta

Dentre os apoıs ı ecebıdos para a realızação das lavouras, os indlgenas de todas as Tls dcstacaram o recebimento de sementes como um recurso importante para todas as unidades famulares Contudo registraram que tal auxílıo fornecido pela Funal, prefeituras munıcipais e orgãos estaduaıs tem sıdo insuficiente do ponto de vista quantıtatıvo

Nesta perspectıva, cabe fazer uma reflexão sobre a seguinte questão ao se incentıvar a agrıcultura de grande extensão e produtıvista não se estarıa colocando em rısco a agrıcultura dıversıfıcada tradıcıonal dos Kaingang? Com os incentıvos dırecıonados a produção de soja não 
incentıvamos, por exemplo, o cultıvo de produtos comercialmente valorizados em detrimento dos produtos destınados ao consumo do grupo, de caráter sustentável ou seja, aqueles baseados nos conhecimentos tradicionais de práticas menos predatonas do ponto de vista ambiental Por outro lado, os dados indıcam que apenas parte das famlıas utılıza o modelo produtıvısta o que revela tambem, que há privılégı para alguns no uso da terra - concebida como comunitárı - em detrimento da maıorıa Essas questões ındıcam que são necessárıos estudos mais aprofundados para avalıar os beneficıos e os danos consequentes dessa pratica agrícola para os Kaingang

A TI Xapeco, em partıcular, contırma de modo exemplar o que se acabou de afırmar A ultıma unıcıatıva tomada nesta dıreção fol a crıação de uma cooperatıva, com 25 socios fundadores, denomunada "Cooperundígena" Voltada ao cultıvo em grande escala de produtos valorızados comercialmente, essa cooperativa tem contado com financiamentos do Banco do Brasıl Segundo Fernandes (2001, p 60) na safra 2000/01 "a cooperatıva atendeu pequena parcela da comunıdade ( $15 \%$ das famílıas undígenas) [ ] e utılızou terras de algumas famílıs para o desempenho das lavouras mecanizadas [ ]" Também por meı da Coopermdígena, foram repassados os funanciamentos provenientes do PRONAF para um total de 350 famílıas kaingang na safra 2002/03

A constıtuıção da Cooperindıgena é uma experiêncıa relatıvamente nova, que tem envolvido poucos grupos domésticos Em passado recente dessa TI, experıência sımılar teve como consequência o favorecımento de poucas famılias, especialmente as mais identıfıcadas com esse modelo produtivista, em detrimento da maior parte do conjunto delas, razão pela qual a inıcıatıva merece maıor acompanhamento e fiscalızação

Não se pode esquecer que alem das famílıas que estão diretamente vınculadas à Cooperındıgena, mantêm se, na TI Xapecó, a agrıcultura pratıcada pelos grupos doméstıcos e o assalariamento interno e externo Contudo, há indıcações de que algumas famílıas sentıram-se prejudicadas ao verem suas terras de cultıvo sendo apropriadas para a realızação de lavouras destınadas exclusıvamente ao comércıo Destaque-se aquı que tais terras têm uso tradicıonal, respeitando-se acordos de ocupação socioespacial implantados há muito tempo 
Outro aspecto a que se deve chamar a atenção e que tal agricultura viabılıza, indıretamente, a aproprıação de terras indıgenas como recurso produtıvo que se integra à produção agncola do munıcípı

É umportante lembrar que os recursos da TI, inclumdo suas terras, são patrımônı de todas as famılıas alı estabelecıdas A exploração produtıvista não necessarıamente deve ser evitada, mas é importante garantır às famílıas não partıcıpantes daquele sistema que recebam compensações que poderıam ser traduzıdas por maır apoı na realızação de suas lavouras tradıcıonaıs Há, portanto, que se respeitar o modo e a quantıdade a se produzır dos diferentes grupos doméstıcos, consıderando-se que produzır para comercialızar pode não ser o desejo de todos Vale, tambem, ressaltar que, apesar de se tratar de um unico grupo étnıco, há entre estes indígenas aqueles que se identıfıcam mais com a cultura tradicional e outros que assimilaram valores da cultura não indigena Neste contexto, recomenda-se o apolo a ambas as formas de produção, implantando-se polítıcas públicas que atendam as famílıas desprivilegiadas que vivem nesta TI, conforme expressa Fernandes (2001, p 62)

Quanto a comercıalızação, os produtos são vendıdos nas ımedıações das TIs Se em grande quantıdade, a comercıalızação se dá junto às cooperatıvas, aos cerealıstas e a grandes comerciantes Se em pequena quantıdade, a produção é utılızada, também, na troca de produtos junto aos comerciantes proxımos da TI ou que estão estabelecıdos no interıor da area indigena

As famílıas kaungang partıcıpam também de feıras, sendo apoiadas e incentıvadas por ONGs, prefeitura municıpal de Chapecó, Funal e outras instıtuições Entre essas ferras, ha uma que merece destaque Trata-se da Feura Agroecológica realızada em Chapeco, apoiada pela Unochapeco, ocasıão em que 15 famílias kaingang da TI Conda vendem seus artesanatos, produtos agrícolas e ervas medicinals Por tratar-se de uma inıciativa da universidade, ha o envolvimento de professores e alunos dos cursos de Ciêncıas Agrícolas e Agronomıa, que partıcıpam da organızação providenciando, mclusıve, transporte para os indígenas

Dentre as fontes de renda indicadas pelos Kaungang de todas as áreas, são invarıavelmente lembrados os "benefícıos" do INSS (apo- 
sentadorıas ruraıs) as pensões, os auxılıos à natalıdade e à deficıêncıa fisıca como recursos undıspensaveıs para a sobrevivêncıa São tambem mencionados os salarıos dos indigenas que pertencem aos quadros de funcionárıos da FUNAI, os contratos da Funasa, e das Secretarias estaduaıs e munıcıpars de Educação ${ }^{18}$

Esses recursos são fundamentais para os grupos doméstıcos, pols garantem a subsistência tanto de famlias nucleares quanto extensas Constatou-se que grande parcela desses rendımentos são gastos na aquisıção de gêneros alımentıcıos, como banha cafe, açúcar, sal, farınha de milho, arroz, feı̃ão, macarrão, trıgo leıte em po, doces carne, além de roupas e produtos de limpeza e higıene, adquirıdos em casas comerciaıs localızadas no interıor e fora da TI

Além disso, os indígenas returam desses mesmos iecursos uma pequena parte para fınanciar suas proprias roças Em alguns casos, os recursos advindos das fontes acima citadas servem como credlto junto ao comercio local, que lhes adianta os insumos agrícolas quando necessario

Por outro lado, na reprodução das unıdades famılıares, a venda da força de trabalho tem sido estrategia recorrente em todas as TIs, aında que a atıvıdade ocorra em menor escala na Aldeıa Condá A venda da força de trabalho não e uma prátıca nova Os indigenas trabalham como diarıstas ou por empreitada nas lavouras dos regionais em serviços como a quebra e a colheita do milho, colheita do feı̃ão e limpeza de roças Nessa relação de trabalho os indigenas não mantêm nenhum vínculo empregatícı com os agricultores que os empregam, o que traz vantagens para o contratante que se libera dos encargos sociais demandados por esses tipos de contrato

$\mathrm{Ha}$, anda, indigenas que trabalham em avarıos como carrega dores de frango tambem como coletores de maçãs em areas curcunvızınhas às TIs Trabalham, aında que esporadıcamente, no corte de erva mate e na produção de mılho para semente

Essas atıvıdades, porem, são lımıtadas pelo calendárıo agrıcola, e estão disponıveıs apenas em determinados peı́́odos do ano Os indígenas indicaram, invariavelmente, que no penodo da entressafra têm maıor necessıdade de alımentos, trazendo consequêncıas para a saude Há que se lembrar aunda, que nos ultımos 30 anos, a região 
em que se encontram inserıdas as TIs sofrem sıgnifıcatıva mudança no processo de produção agricola A introdução do modelo produtıvısta com a adoção do sıstema mecanızado dımınuıu bastante a oferta de trabalho tanto para os regionais quanto para os indigenas

Outra fonte de recursos a ser mencionada dız respeito à exploração efetıvada por indıgenas de jazıda de pedras semıpreciosas na TI Xapeco, paia os quais esta atıvidade constıtuı outra fonte de renda

Dentre as alternatıvas de trabalho temporarıo que se têm apresentado aos Kaingang mais especificamente para os da TI Xapecó, destaca-se a contratação de mão-de-obra indıgena no perıodo de construção da hıdreletrica Quebra QueıXo ${ }^{19}$, sıtuada no rıo Chapeco, a dez quilômetros dos limites atuals dessa TI

A notıcıa da implantação desse empreendımento gerou expectatıva entre os Kaingang sobre a possibilıdade de executar algum trabalho na obra que lhes rendesse um adicional no sustento de suas famílıas, o que efetıvamente ocorreu, mas não na dımensão esperada Vale lembrar que esta hidrelétrıca esta situada dentro da area reservada aos Kaingang em 1902, o que lhes da entendimento de que estariam trabalhando dentro de suas terras tradicionais

Inserır-se como trabalhador assalarıado rural na sociedade regınal ou no interıor da TI não é o desejo, nem faz parte da tradıção kaingang Trata se na verdade, de um últumo recurso a que os indígenas têm recorrıdo sıstematıcamente por falta de outras opções

São as redes de sociabılıdade desenvolvidas entre os indigenas e os moradores regıonaıs que garantem o acesso ao trabalho temporárıo No caso da Aldeıa Conda, cujas redes ainda estão pouco estabelecıdas, dada a ındefınıção em relação à terra, esse tıpo de trabalho e pratıcamente ausente restando lhes apenas a alternativa do artesanato

Diferentemente de outras atividades que apresentam sazonalıdade, a confecção de objetos em taquara e cıpo, tradıcıonal entre os Kaingang, ocorre com intensidade variavel durante todo o ano o que assegura recursos para as familias nos períodos de escassez

Na TI Conda, a produção do artesanato é consıderada a prıncıpal atıvidade na TI Xapeco, esta atıvidade representa menos de $5 \%$ da renda famuliar, e na TI Chımbangue está restrıta a eventuaıs encomendas de cestos e balaios por parte dos regionais 
Um aspecto dessa produção artesanal que merece ser ressaltado dız respeito ao controle que as famílıas indígenas mantêm sobre o processo produtıvo A tecnologı utılızada na confecção de peças e tradıcıonal transmitıda as novas gerações no interıor das unıdades domésticas Contudo, reclamam da falta de materıa prima no interıor das TIs, havendo, por vezes, necessıdade de contratar um camınhão para transporta-los a locais distantes para extrair os cipos e taquaras de que necessitam para produzir o artesanato

Fıca evidente a necessıdade de uma revısão das atuaıs polıtıcas de gerenciamento e estímulo da produção indigena em seus diferentes setores para que se possa, a partır de um detalhado dıagnóstıco, reorıentar algumas delas em dıreção a inclusão, de modo sustentavel, da totalıdade da população das diferentes terras indıgenas Kaıngang de Santa Catarina

\section{Consıderações finais}

O processo de colonızação do oeste catarmense promovido pelo governo brasıleiro, em sua fase maıs recente, atraıu para a região migrantes agricultores orıundos, na maıorıa, do Rıo Grande do Sul A piesença destes novos habitantes acentuou as transformações de ordem ambiental, que vinham ocorrendo e, em consequência, provocou profundas transformaçôes na cultura dos povos indigenas do local

A omissão e a incompetência do Estado brasıleiro no que se refere ao dureito dos indıgenas possibilıtou aos colonos a apropriação dessas terras, bem como o seu registro de propriedade Para os Kaungang restaram, além da exproprıção das terras, o decrescımo populacıonal e aunda o confinamento em reduzidos espaços do oeste catarmense Somente na decada de 1980, com a democratızação do país, é que os movimentos indigenas encontraram condıções para recuperar parte de suas terras

O presente estudo constatou que a situação socioeconômıca dos Kaingang que hoje habitam as TIs de Santa Catarına não apresenta melhorıas sıgnifıcatıvas de sua condıção socıal Regıstrou aunda que eles reıvındıcam polıtıcas publıcas que ofereçam orıentação técnıca fı nanciamentos e projetos sustentaveis para desenvolver suas atıvidades agricolas Contudo, entende se que a política publica voltada para a produção agricola devera respeitar as especıfıcıdades da cultura indíge- 
na, viabilızando projetos alternatıvos ao modelo agrícola produtıvista com o qual apenas parte das familias indígenas se indentıfica

Quanto as reıvındıcações atuaıs para a recuperação de parcela de suas terras regıstra se a ınoperâncıa do Estado brasıleıro na solução dessas questões Em parte, o protelamento da solução se deve a resıstêncıa daqueles que ocupam as terras indigenas, por vezes apolados por polítıcos locaıs com os quaıs cultıvam relações clıentelıstıcas

No que se refere às sociedades indígenas, a Constituıção de 1988 reconheceu direitos sociais entre os quals o dıreıto a terra de uso tradıcıonal Para que tal dıreito fosse incluıdo na "Constıtuıção Cıdadã houve o envolvimento, principalmente dos povos indigenas do ternitorio nacional, mas tambem da sociedade civil que se pronunciou através de diversos movimentos sociais

Concluindo, e preciso enfatizar que os direitos constitucionais devem ser garantıdos a todos os cadadãos brasıleiros, incluundo-se, entre estes, os povos indıgenas, com os quaıs o Estado brasıleiro possuı uma dıvida hıstorıca Afınal, somos um pais multiétnıco, e e assım que devemos nos identificar e nos respeitar

\section{Notas}

1 A realızação da pesquisa da qual resultou este livro for estımulada pelo professor Sílvio Coelho dos Santos coordenador do Nucleo de Estudos sobre Populações Indıgenas (NEPI) do Programa de Pos Graduação em Antropologia Social da UFSC

2 Sobre o processo de expropriação das terras dos indıgenas em Santa Catarına veja se especialmente os trabalhos de Santos (l970 $1978 \quad 1981 \quad 1985$ 2003)

3 Os Kaingang encontram se localizados em 28 TIs duas no Estado de São Paulo 11 no Estado do Parana quatro no Estado de Santa Catarma e 11 no Rio Grande do Sul No estado catarinense as TIs Xapeco Toldo Pinhal Toldo Chimbangue e Rıo dos Pardos estão sob a responsabılıdade da ADR/Funal de Chapeco Esta ADR atende aunda a TI Palmas localızada no Estado do Parana e a TI Nonoal situada no Estado do Rıo Grande do Sul

4 Não foram computados neste total 260 indıgenas resıdentes na cidade de Chapeco categorizados como desaldeados nos registros da Funasa

5 O crescimento populacional desta TI pode ser acompanhado pelos seguntes registros em 1969 a população somava um total de 1010 indıvıduos (Santos 1970) em 1980 consistia em 1864 pessoas (Nacke 1983) e em 1995 totalizava 3214 undıvıduos Em 2007 dados da Funau ındicam a presença de 4768 da etnıa Kaingang e apenas 60 da etnia Guaranı

6 Sobre o processo de recuperação dessas terras veja se o Laudo Antropologico elaborado pelas antropologas Ana Lange (Funal) Aneliese Nacke (UFSC) e Neusa

\section{ILHA}


Marıa Sens Bloemer (UFSC) (1984)

7 Em 1985 por ocasıão da elaboração do Laudo Antropologıco resıdıam nestas terras 90 pessoas em 1995 esta população indıgena era de 222 indıviduos (Bloemer e Nacke 1995) e atualmente somam 434 individuos (FUNAI 2007b)

8 Dados coletados por Cabral Jr (1993) indicam 35 familias vivendo nessa area Atualmente residem nesta Terra Indigena 121 individuos (FUNAI 2007b)

9 Este Laudo Antropologico for elaborado pelo antropologo Ricardo Cid Fernandes a partır da nomeação da Funai pela Portarıa n'020/PRES (18/01/2002) Atualmente ha um processo na justıça aguardando analıse e emıssão de portarıa declaratoria (FUNAI 2007a)

10 E preciso dizer que as cidades excrcem grande fascinıo sobre as populações indıgenas em geral visto que concentram a tecnologia do branco os grandes espaços de compra e venda [ ] as cldades com seus ıcones da civllızação concentram e expressam o poder simbolico do homem branco (Tommasino $2000 \mathrm{p} \mathrm{38 \text {) }}$

11 O estudo foı realızado por solıcitação da FUNAI - ADR de Chapeco/SC em 1988 pel z equipe multidısciplinar de antropologos Kimıye Tommasino Vilson A Cabral Jr Jussara Cappuccı Marcelo C Rosa Marco A Dinhame

1 Residem nesta Tl atualmente 327 pessoas (FUNAI 2007b)

13 Essas terras dependem anda de regularızação A compra do restante da area 1052 hectares anda deve ser for efetivada (FUNAl 2007a)

14 Palestra intıtulada Fconomı Tradicional Guaranı e Kaingang proferıda no Encontro sobre Agricultura Indigena realızado nos dias 1 I a J4 de agosto de 1988 em Curitiba/PR promovido pelo CIMI Regional Sul

15 Grupo domestico e essencialmente uma unidade de familia e de economia domestica organizada para prover recursos materiais e culturais necessarıos para manter e criar seus membros (Fortes 1974 p 87)

16 Trata se de uma pratica de ajuda mutua utılizada pelos Kaingang para realızar as roças dos produtos potencialmente comercialızaveıs como mlho e feı̃ão $E$ indıcado tambem como um momento de socialızação

17 De acordo com Steward (1948) e Santos et al (1998) a colvara ou quemada indıgena e um sıstema ecologicamente adaptado a utılização do solo florestal Ela e praticada numa area limitada que depors de alguns anos e abandonada convertendo o local numa mata secundaria beneficiada com algumas especies de uso humano A aplıcação que os descendentes europeus fizeram da queımada e que deve ser critıcado a medıda que inviabılıza a regeneraçao das matas

18 Entre as atıvidades profissionais desenvolvidas constatam se as de motorista tratorısta tecnico agrıcola engenheiro agrônomo agente sanıtarıo agente de saude auxilıar de enfermagem professor merendeira diretora de escola

19 A hidreletrica Quebra Queixo fol implantada no rıo Chapeco afluente do rio Uruguai nas divisas dos municıpıos de São Domıngos e Ipuaçu (SC) tendo provocado o deslocamento de 135 familias aproximadamente Sua potencia instalada e de $120 \mathrm{MW}$

\section{Referências}

BLOEMER Neusa $M$ Sens NACKE Aneliese Revisitando o Toldo Chım bangue Revista de Antropologıa São Paulo Universidade de São Paulo v 39 n 2 p 1992181995 
A precarızaçao de politıcas publıcas e suas

lepercurssoes na auto sustentaçao dos Kaingang do oeste catannense

BRASIL Constituição (1988) Constitutção da Republica Federattva do Brastl Brasilia DF Senado 1998

CABRAL JUNIOR Vilson Antônıo Uma constelação permeada de tensão Kaingang e colonos no Punhal Trabalho de Conclusão de Curso (Gradua ção em Ciêncıas Socıaıs) - Departamento de Ciêncıas Socıaıs Unıversıda de Federal de Santa Catarma Florianopols 1993

FERNANDES Ricardo Cid Laudo antropologico impactos da UHE Quebra Queixo sobre a terra indigena Xapeco Florianopolis 2001

FERNANDES Ricardo Cid Laudo antropologico re estudo dos limites da terra undigena Toldo Pmhal Florianopolıs 2003

FORTES M O ciclo do desenvolvimento do grupo domestico Cadernos de Antropologia Brasilia Ed da UnB n 61974

FUNDAÇÃO NACIONAL DO INDIO (FUNAI) Sıtuação fundıarıa das terras indigenas jurısdicionadas a AER Chapeco 2007a Impresso

FUNDAÇÃO NACIONAL DO INDIO (FUNAI) Terras e populações indigenas em Santa Catarina 2007b Texto digitado

FUNDAÇÃO NACIONAL DE SAUDE (FUNASA) Minısterıo da Saude Polı tica Nacional de Atenção a Saude dos Povos Indigenas Brasílua 2000

FUNDAÇÃO NACIONAL DE SAUDE (FUNASA) Minısterıo da Saude Re latorto das princtpats atividades e resultados - 1999 a 2002 Brasilia dez 2002

FUNDAÇÃO NACIONAL DE SAUDE (FUNASA) IDSI Plano Distrital de Sau de Coordenação Regıonal de Santa Catarına Dıstrıto Sanıtarıo Especial Indigena Interior Sul 2003

MELIA Bartolomeu Economia tradicional Guaranı e Kangang ln EN CONTRO SOBRE AGRICULTURA INDIGENA 1988 CIMI Regional Sul Curitiba II a 14 de agosto Anals Curitiba 1988

NACKE Aneliese BLOEMER Neusa M Sens LANGE Ana Laudo antropo logico Toldo Chtmbangue Florianopolıs UFSC Brasilıa Funaı 1984

NACKE Anelıese $O$ indıo e a terı a luta pela sobrevivêncıa no PI Xapeco Dissertação (Mestrado em Ciências Sociais) - Centro de Filosofia e Cl êncıas Humanas Unıversıdade Fedcral de Santa Catarına Florlanopolıs 1983

OLIVEIRA R C de Identıdade etnia e estrutuia soctal São Paulo Pioneira 1976

PIAZZA Walter Fernando Santa Catarma sua histon UFSC Lunaidell 1983

RENK Arlene Territorio e alterıdade construções socials do oeste catanı nense In NACKE Aneliese et al Os Kaingang no Oeste Catarmense tradıção e atualidade Chapeco Argos 2007

SANTOS Silvio Coelho dos A integração do indio na sociedade regional Floria nopolis Ed da UFSC 1970

SANTOS Sılvıo Coelho dos Indıgenısmo e expansão capıtalısta faces da agonıa Kaingang Cadernos de Ciências Socıaıs Departamento de Clências Soclaus da UFSC Florianopolıs v 2 n 21981 
SANTOS Silvio Coelho dos Os povos indigenas e a Constituinte Porto Alegre Movimento Flonanopolis Ed da UFSC 1989

SANTOS Sílvio Coelho dos et al (Org) Sociedades indigenas e o Direito uma questão de dıreıtos humanos Flonanopolıs Ed da UFSC CNPq 1985

SANTOS Silvio Coelho dos et al Estudo etnografico da usina hidreletrica Ma chadinho Florianopolıs UFSC 1998 Relatorio Final Fapeu Projeto 145

STEWARD Julıan $\mathrm{H}$ Culture areas of the tropical forests In (Ed) Handbook of South American Indians the tropical forest tribes Washington DC Smithsonian Institution, Bureau of American Ethnology 1948 v 3 p 883899

TOLEDO Victor $M$ A racionalıdade ecologica da pequena produçăo campo nesa Agroecologia e Desenvolvimento p 18 26, 1998

TOMMASINO Kumiye A historia dos Kaingang da Bacta do Tibagl uma socie dade Jê Meridıonal em movimento Tese (Doutorado em Antropologıa Socıal) - Departamento de Antropologıa Unıversıdade de São Paulo São Paulo 1995

TOMMASINO K Apresentação In MOTA L T (Org) As cidades e os povos indigenas mitologias e visões Marınga EDUEM 2000 